\title{
Commentary: Two chests are better than one
}

\author{
Chadrick E. Denlinger, MD \\ From the Division of Cardiothoracic Surgery, Department of Surgery, Medical University of South Carolina, \\ Charleston, SC. \\ Disclosures: Author has nothing to disclose with regard to commercial support. \\ Received for publication July 21, 2019; accepted for publication July 22, 2019; available ahead of print Sept 10, \\ 2019. \\ Address for reprints: Chadrick E. Denlinger, MD, Division of Cardiothoracic Surgery, Department of Surgery, \\ Medical University of South Carolina, 114 Doughty St, Charleston, SC 29425 (E-mail: denlinge@ musc.edu). \\ J Thorac Cardiovasc Surg 2019;158:1718-9 \\ $0022-5223 / \$ 36.00$ \\ Copyright (C) 2019 by The American Association for Thoracic Surgery \\ https://doi.org/10.1016/j.jtcvs.2019.07.063
}

Living donor lung transplantation represents a substantial portion of all lung transplants in Japan. ${ }^{1,2}$ Reported outcomes of living donor transplants are comparable, and at times better than, outcomes of patients transplanted with cadaveric donor lungs. Sugimoto and colleagues $^{2}$ recently demonstrated that the overall and chronic lung allograft dysfunction survival rates were similar between recipients of living donor lungs compared with standard cadaveric donors. The development of restrictive allograft dysfunction was less severe and delayed among patients with living donors compared with cadaveric donors. ${ }^{2}$ In this comparison, the disease severity of living donor recipients was greater than cadaveric donors as indicated by a significantly greater calculated lung allocation score. Similar results were published by Date and colleagues, ${ }^{3}$ who compared a cohort of 42 living donor transplants to 37 recipients of cadaveric lungs. This group reported impressive 1- and 3-year survival rates of transplants. ${ }^{3}$

In their most recent article, Kayawake and colleagues ${ }^{4}$ from Kyoto University expanded on their previous cohort and compared the gain in pulmonary function of recipients with the lost pulmonary function among their donors. The and forced expiratory volume in 1 second following transplant among 21 of 38 living donor recipients with both pre- and postoperative pulmonary function tests was greater than the amount of lost pulmonary function among the living lobar donors. The loss in donor forced vital capacity of $18 \%$ and forced expiratory volume in 1 second of $16 \%$ following lobar donation is commensurate with the loss in pulmonary function following resection for lung cancers. Previous studies have similarly shown that the decrease in pulmonary function is often less than the calculated values based on preoperative pulmonary function tests and the number of pulmonary segments resected. ${ }^{5}$ This suggests that the greater expansion of the remaining lung parenchyma contributes to greater spirometric measures. From $89.7 \%$ and $88.3 \%$ for recipients of living donor lung authors determined that the increased forced vital capacity

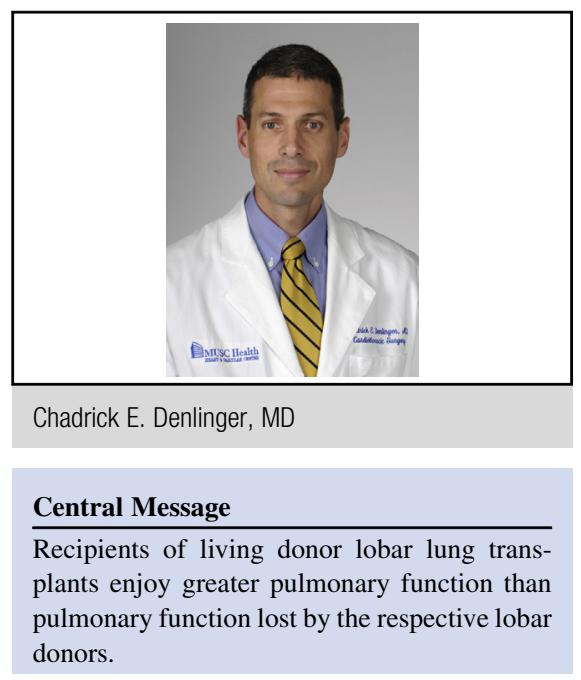

See Article page 1710 .

this perspective, one may expect that the spirometry of 2 transplanted lobes into a vacant chest would exceed the loss of pulmonary function from the respective donors whose remaining lobes now have more room to expand.

In addition to demonstrating excellent pulmonary function, the authors also demonstrate excellent long-term survival of the transplant recipients. ${ }^{4}$ However, the inclusion criteria for this retrospective analysis should be noted. During the defined study period, 76 living donor lobar transplants were performed. Understandably, the 24 patients with either upper lobe-sparing transplants or single-lung transplants were excluded. From the remaining 52 patients who underwent bilateral lobar transplant, only the 38 patients who survived at least 1 year and had pulmonary function tests evaluated during the first year following transplant were included in the analysis. This selective cohort was used to determine changes in recipient pulmonary function. This selected cohort of patients who survived the first year following transplant was also used to determine the 5-year survival, which was excellent.

\section{References}

1. Komatsu M, Yamamoto H, Shomura T, Sonehara K, Ichiyama T, Urushihata K, et al. Twenty-year follow up of the first bilateral living-donor lung transplant in Japan. Intern Med. July 19, 2019 [Epub ahead of print].

2. Sugimoto S, Yamamoto H, Kurosaki T, Kurosaki T, Otani S, Okazaki M, et al. Impact of chronic lung allograft dysfunction, especially restrictive allograft syndrome, on the survival after living-donor lobar lung transplantation compared with cadaveric lung transplantation in adults: a single-center experience. Surg Today. 2019;49:686-93. 
3. Date H, Sato M, Aoyama A, Yamada T, Mizota T, Kinoshita H, et al. Living-donor lobar lung transplantation provides similar survival to cadaveric lung transplantation even for very ill patients. Eur J Cardiothorac Surg. 2015;47:967-72.

4. Kayawake H, Chen-Yoshikawa TF, Hamaji M, Nakajima D, Ohsumi A, Aoyama A, et al. Acquired recipient pulmonary function is better than lost donor pulmonary function in living-donor lobar lung transplantation. J Thorac Cardiovasc Surg. 2019;158:1710-6.e2.

5. Zeiher BG, Gross TJ, Kern JA, Lanza LA, Peterson MW. Predicting postoperative pulmonary function in patients undergoing lung resection. Chest. 1995;108: 68-72. 